(C)2017, Elsevier. Licensed under the Creative Commons AttributionNonCommercial-NoDerivatives 4.0 International http://creativecommons.org/ about/downloads 


\section{Support needs of adolescents' post-cancer treatment: a systematic review.}

\section{Yousuf Ismail $^{1}$ and Julie Hendry ${ }^{2}$}

\footnotetext{
${ }^{1}$ Student radiographer, Kingston University and St. George's, University of London, United Kingdom. Email:y.ism@ hotmail.com. Address: 7 Summerleaze, Bristol, BS16 4HD.

${ }^{2}$ Course director: BSc (Hons) Therapeutic Radiography, Kingston University and St. George's, University of London, United Kingdom. Email: j.hendry@sgul.kingston.ac.uk
} 


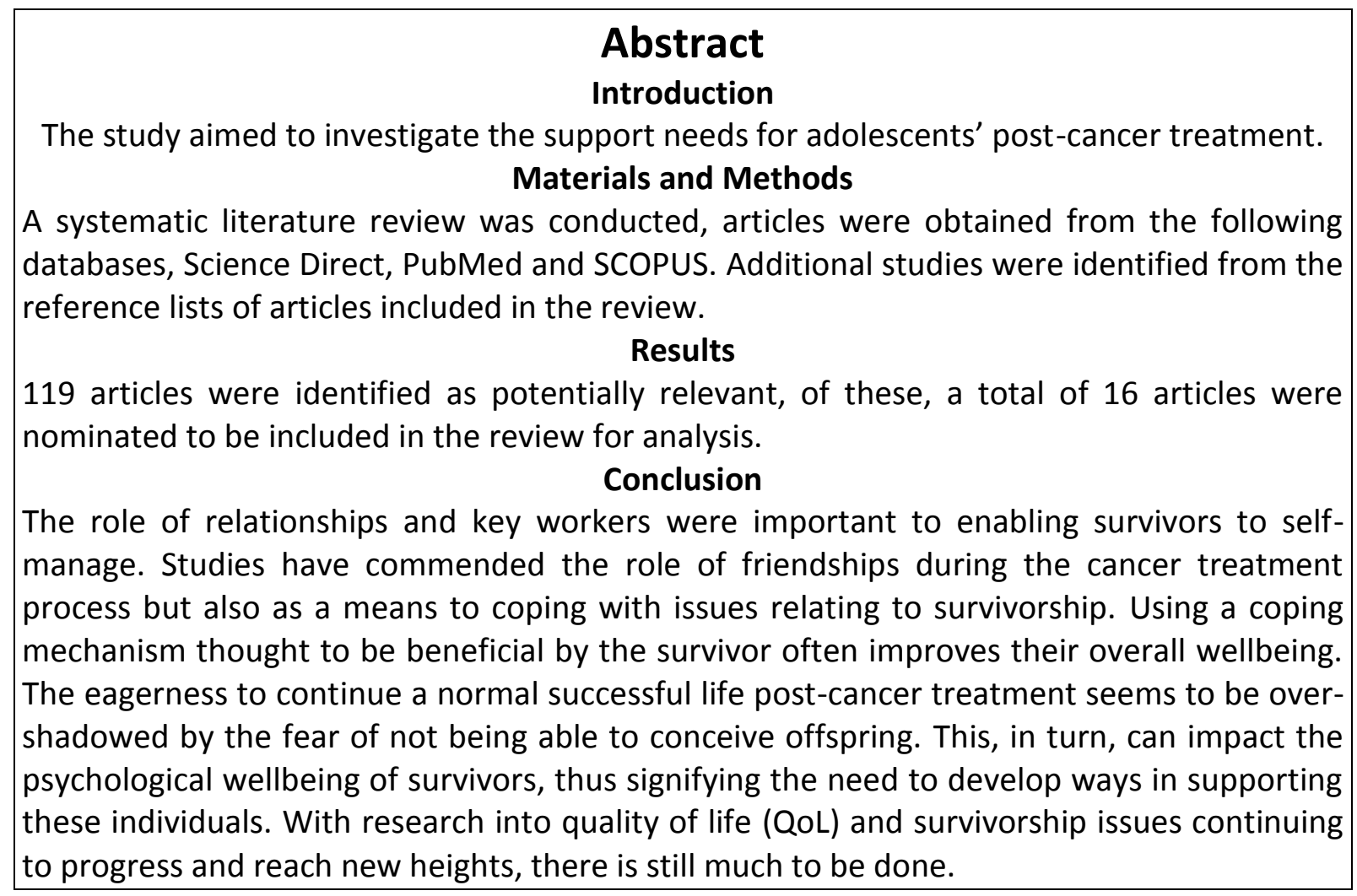




\section{Highlights}

- No definitive means of combatting survivorship issues

- Many AYA may appear to have managed well following treatment

- Impact of treatment becomes apparent subsequently, 'hiatus in care'. 


\section{Support needs of adolescents' post-cancer treatment: a systematic review.}

Abstract
Introduction
Materials and Methods
The study aimed to investigate the support needs for adolescents' post-cancer treatment.
A systematic literature review was conducted, articles were obtained from the following
databases, Science Direct, PubMed and SCOPUS. Additional studies were identified from
the reference lists of articles included in the review.
Results
$\begin{aligned} & 119 \text { articles were identified as potentially relevant, of these, a total of } 16 \text { articles were } \\ & \text { nominated to be included in the review for analysis. } \\ & \text { Conclusion } \\ & \text { The role of relationships and key workers were important to enabling survivors to self- } \\ & \text { manage. Studies have commended the role of friendships during the cancer treatment } \\ & \text { process but also as a means to coping with issues relating to survivorship. Using a coping } \\ & \text { mechanism thought to be beneficial by the survivor often improves their overall } \\ & \text { wellbeing. The eagerness to continue a normal successful life post-cancer treatment } \\ & \text { seems to be over-shadowed by the fear of not being able to conceive offspring. This, in } \\ & \text { turn, can impact the psychological wellbeing of survivors, thus signifying the need to } \\ & \text { develop ways in supporting these individuals. With research into quality of life (QoL) and } \\ & \text { survivorship issues continuing to progress and reach new heights, there is still much to be } \\ & \text { done. }\end{aligned}$

Keywords:

Survivorship; Quality of life; Psychosocial issues; Support needs; Support options; Infertility; Body image; Anxiety; Social support. 
In the United Kingdom, it is estimated that 2,300 adolescents aged between 15-24 years old are diagnosed with cancer each year ${ }^{1}$. Due to the advancements in cancer treatment, there have been notable improvements regarding the survival of persons diagnosed with cancer during adolescence ${ }^{2}$. Cancer Research UK reports that the 5-year survival rate amongst adolescents and young adults (AYA) is approximately $80 \%{ }^{1}$. Therefore, it is crucial to recognise 'survivorship' as a unique stage of the cancer trajectory ${ }^{3}$.

Transition into life after cancer, side effects from treatment and anxiety of the risk of a recurrence can inflict different emotions and require different levels of support to meet the needs of the individual ${ }^{3}$. A study uncovered the significance of alopecia on a person's self-perception which in turn promotes body image dissatisfaction, low self-esteem and many other characteristics that are prevalent among AYA currently undergoing cancer treatment ${ }^{4}$.

Although some of the psychosocial pressures begin to ease post-cancer treatment, further problems arise long-term that gravely affect the mental health of AYA cancer survivors $^{5}$. Long-term AYA cancer survivors report a higher incidence of anxiety and depression, which impedes on their ability to gain employment or educational credentials ${ }^{5}$. As the burden of cancer remains, the safeguarding of the survivors' QoL has become increasingly important and plays a fundamental role in the evaluation of cancer therapy ${ }^{6}$.

The aim of the systematic review is to clarify the needs of AYA post-cancer treatment and exploring the support options available. 
The electronic databases Science direct, PubMed and SCOPUS were reviewed, these particular databases were chosen due to their accessibility of numerous peer-reviewed journals. The use of Boolean operators allow the author to narrow the search to retrieve articles most relevant to the research quesiton ${ }^{7}$.

\section{Search terms}

The search terms included combinations of the following phrases or keywords: "adolescents OR young adults OR teenagers" AND "support needs OR quality of life OR support available OR psychosocial support" AND "post-cancer treatment OR after cancer".

Inclusion and Exclusion criteria,

Inclusion criteria included articles: (1) published in English; (2) in a peer-reviewed journal; (3) access to full text; (4) published between January 2004 and August 2016.

Exclusion criteria: (1) participants outside the age constraints (12-26 years old); (2) the studies aim not directly relevant to core concepts of support needs, QoL or support availability for AYA post-cancer treatment; (3) lack of qualitative synthesis. 


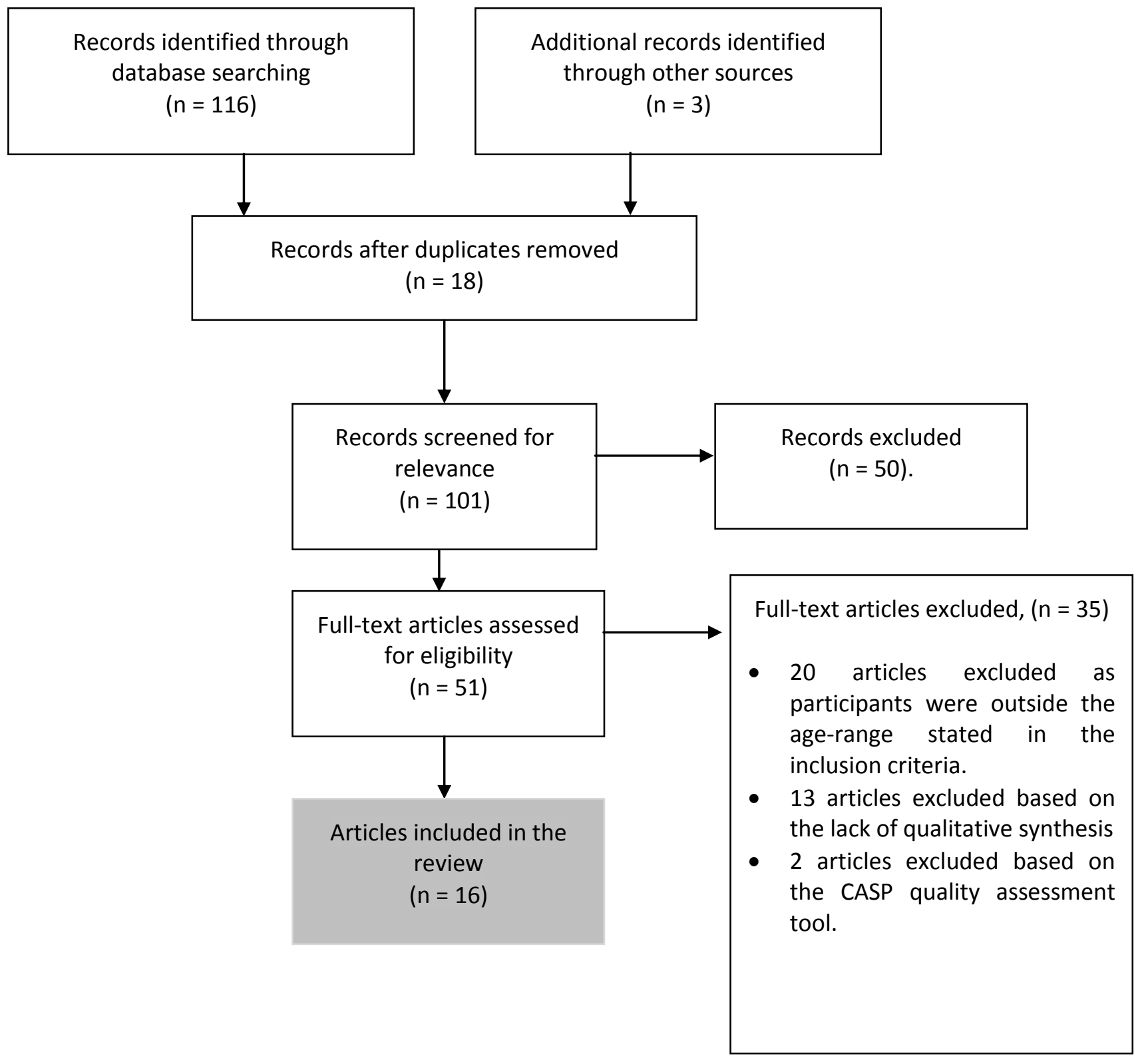

Figure 1: Outcome of the search strategy and the decision-making model 
Reference lists of selected papers were reviewed for additional articles that may be pertinent to the study and seen as a necessary step when conducting a review ${ }^{8}$. Grey literature also provides a sound grounding on the current understanding of issues around support post-cancer treatment ${ }^{8}$. Hence the inclusion of key documents relating to AYA survivorship will be included in the review.

All articles included in the review were subject to attaining ethical approval. Ethics play a vital role in ensuring all researchers are held accountable to upholding the rights and dignity of participants in their research, this is especially important due to the vulnerability of the participants in question ${ }^{9}$.

The quality assessment tool used is the Critical Appraisal Skills Programme (CASP) that will determine the final selection of articles ${ }^{10}$. The series of questions used to appraise each article were taken directly from the CASP tool and can be found in Appendix 1.

A total of 16 papers were nominated to be included in the review for analysis. 


\section{Results}

\begin{tabular}{|c|c|c|c|c|c|c|}
\hline No & Author & Study type & Methods & Sample Size. & $\begin{array}{c}\text { Age range of participants. } \\
\text { (years) }\end{array}$ & Key findings. \\
\hline 1 & Barr et al., (2016) & Narrative review & $\begin{array}{l}\text { The study reviewed a } \\
\text { variety of issues } \\
\text { ranging from } \\
\text { financial issues, } \\
\text { psychological } \\
\text { support, sexuality } \\
\text { and body image with } \\
\text { the aim to consider } \\
\text { the opportunity for } \\
\text { progress. }\end{array}$ & - & - & $\begin{array}{l}\text { Establishing a discrete AYA oncology } \\
\text { discipline with related training programs } \\
\text { necessary for health care professionals } \\
\text { to attending to challenges facing AYA at } \\
\text { any stage of the cancer journey. } \\
\text { The introduction to community-led or } \\
\text { internet-based initiatives that recognise } \\
\text { that access to quality care for AYA is a } \\
\text { right, not a privilege. }\end{array}$ \\
\hline 2 & Choquette et al., (2016) & $\begin{array}{c}\text { Semi-structured } \\
\text { interviews }\end{array}$ & $\begin{array}{l}\text { In-depth interviews } \\
\text { were conducted } \\
\text { using an interpretive } \\
\text { descriptive approach } \\
\text { using } 11 \text { adolescents' } \\
\text { post-cancer } \\
\text { treatment. The } \\
\text { transcripts of the } \\
\text { taped interviews } \\
\text { were reviewed by the } \\
\text { study team. }\end{array}$ & 11 & $13-17$ & $\begin{array}{l}\text { Nearly all adolescents were impacted } \\
\text { negatively by the cancer experience } \\
\text { however the ability to maintain } \\
\text { friendships during the transition } \\
\text { emerged particularly salient allowing } \\
\text { adolescents to rise above the challenges } \\
\text { and the residual effects of cancer } \\
\text { treatment. }\end{array}$ \\
\hline
\end{tabular}


Ultimately, the purpose of religion and spirituality is to evaluate and develop targeted intervention efforts. Through more sophisticated study design can research understand how religion or spirituality impacts adolescents' health and wellbeing.

of keywords related

to spirituality and religion.

Different ethical phenomena were examined to form a basis for the ethical standards if clinical trials were to be conducted.

7 studies were

identified from

databases CINAHL, MEDLINE and

PsychInfo. nitial research into oocyte and ovarian cryopreservation stemmed from semen preservation using non-invasive techniques which resulted in the preservation of male fertility. Though the process of preservation of female fertility would improve the morale of patients. The ability to offer this intervention before the commencement of cancer treatment is difficult as there would be a clear risk to health if any kind of cancer treatment is delayed.

Changes in body image have adverse implications on self-esteem and can be moderated through social support. 7 articles included in the review recognise social support as a means to facilitate in adjusting to changes in physical appearance. 
plemented to

address the aims of

the study, which

entailed the

participation of AYA

cancer survivors and

extracting individual

opinions with the

goal of achieving a

consensus among the

$$
\text { group. }
$$

Discussion The approach taken

consisted in

examining the

available evidence

and combining it with

examples of recent

service and research

developments.

$8 \quad$ Michel and Vetsch (2015)

Systematic

review

8 studies were

identified from the

Cochrane database and PubMed.

Six themes were highlighted and given high importance among the

participants, with each individual theme followed with a number of sub-needs. The themes highlighted were;

counselling and psychological support, developing an adaptive social network,

financial support, maintaining a healthy

lifestyle, needs specific to post-cancer treatment and specialised care and

strategies for returning to 'normal' life and adapting to this new role.

Results found improved knowledge in sexual issues resulted in improved selfesteem relating to body image and relationships. The study continued to discuss the option of counselling in the hopes of enhancing psychosexual developments in adolescents.

To be able to improve the quality of follow up care, and identify and treat psychological distress among AYA

cancer survivors, screening tools should be implemented to better identify psychological distress. 


\begin{tabular}{|c|c|c|c|c|c|c|}
\hline 9 & Moody et al., (2014) & Mixed methods & $\begin{array}{l}\text { A mixed-method } \\
\text { approach was } \\
\text { implemented } \\
\text { including surveys, } \\
\text { focus groups and } \\
\text { interviews with AYA } \\
\text { survivors, parents of } \\
\text { survivors and } \\
\text { professionals }\end{array}$ & 24 & $16-24$ & $\begin{array}{l}\text { The study found that survivors need } \\
\text { continuous psychological support along } \\
\text { with relevant information regarding } \\
\text { cancer. Survivors involved in the study } \\
\text { had worries of the future, potential } \\
\text { relapse, body image and infertility. }\end{array}$ \\
\hline 10 & Pacey (2007) & $\begin{array}{l}\text { Literature } \\
\text { review }\end{array}$ & $\begin{array}{l}\text { Critically analysing } \\
\text { articles pertaining to } \\
\text { different methods of } \\
\text { fertility preservation. }\end{array}$ & - & - & $\begin{array}{l}\text { Understanding the effects of the } \\
\text { reproductive system from the cancer } \\
\text { treatments has advanced in recent } \\
\text { years. With assisted conception } \\
\text { improving male fertility, current } \\
\text { treatment options do not prove } \\
\text { beneficial for women in retaining their } \\
\text { fertility post-cancer treatment. } \\
\text { Several different treatment modalities } \\
\text { were discussed, which include } \\
\text { endocrine therapy, in-vitro, use of } \\
\text { artificial gametes and freezing and re- } \\
\text { implantation of gonadal tissue. All } \\
\text { encouraging but require further } \\
\text { research and understanding prior to } \\
\text { clinical use. }\end{array}$ \\
\hline
\end{tabular}


11 Patterson et al., (2015) Narrative review

To review the
medical, psychosocial
and behavioural late

effects; survivorship

care planning and

transition; current

research priorities;

and practice

implications.

Stinson et al., (2015)

Semi- structured

Interviews were interviews.

conducted to better

understand the

issues facing AYA

cancer survivors
Taylor et al., (2013)

\section{Systematic} review
MEDLINE, CINAHL and Psychlnfo were searched for

literature published between 1987 and 2011.

Survivors of cancers in adolescence are confronted with dual demands when transitioning into an independent adult, concurrently with their transition from patient to survivor.

20 had revealed that dating, sexual relationships, fear of infertility and access to care through adolescent friendly and accessible means allow for improvements in support which would ultimately improve psychosocial health of adolescents during and post treatment.

With 17 articles included in the review, 9 common themes were identified: psychosocial function, the importance of peers, the importance of support, the impact of symptoms, striving for normality, impact of diagnosis, positive experiences, and financial consequences. 
the different aspects

of AYA life

throughout the

cancer journey.

\begin{abstract}
NICE improving outcomes
\end{abstract} for children and young

people

(2005)

National Cancer Survivorship Initiative

(2010)
Document

\section{The document sets} out a blueprint for

the NHS in improving

care services for

children a young people.

The document reviewed the current follow up processes and how it could be improved as the number of survivors increases.
Emotional and social sequelae can

impact on AYA QoL, but may be

addressed through survivorship

programs. This allows for AYA to achieve psychological and emotional wellbeing

while being able to to re-start

educational or career pathways.

Appropriate psychosocial support for children and young people including their families is complex and

multidimensional. Support needs are highly individual and will change as the patient and families move through the different stages of the cancer pathway. Psychological services play a crucial role in all stages of the pathway including into adult life. The difficulty to provide adequate support is due to the heavy reliance on voluntary sector funding. NICE recommends lifelong contact with cancer centres though with increasing survivorship the capacity to continue seems unlikely. Improving quality of life is not just adding years to one's life but adding life to years ahead. A shift to a stratified pathway in lieu of a 'one size fits all' will allow professionals to tailor support to meet individual needs.

Individuals should be encouraged to self-manage with the right tools and information from professionals. 
Though it was evident that there is a paucity of articles pertaining to psychosocial related issues, it was disappointing that only 4/16 were qualitative studies. Fan and Eiser (2009) recognised social support as a means of enabling survivors to adjust to changes in their physical appearance, and may in the future play a critical role in improving the QoL for AYA following cancer treatment ${ }^{11}$.

Kelly (2013) discussed the introduction of strategies and survivorship programs aimed at enhancing QoL and survivorship ${ }^{12}$. The National Cancer Survivorship Initiative perceives QoL as not only adding years to one's life but adding life to years to come ${ }^{13}$. Teenage Cancer Trust (2015) also discussed the introduction of survivorship programs which may allow for AYA to achieve psychological and emotional wellbeing to be able to re-start educational or career pathways ${ }^{14}$.

Follow up for cancer survivors begins with regular clinic attendances for review by their oncologist; subsequently these reduce to bi-annual or annual visits. Where possible, all patients should be reviewed by an MDT and sufficient information provided to all patients to enable them to self-manage ${ }^{13}$. Support needs are highly individual and therefore providing a more stratified support pathway is necessary ${ }^{15}$. Current support channels for cancer survivors rely heavily on voluntary sector funding and therefore providing life-long support for all patients is impractical ${ }^{15}$. Establishing a discrete AYA oncology discipline with related training programs via community-led or internet-based initiatives may well impact positively on the lives of the survivors ${ }^{16}$.

The role of relationships, whether sexual or otherwise does ultimately impact the psychosocial wellbeing of the survivors ${ }^{12,17}$. The significance of infertility was evident among the studies ${ }^{17,18,19}$, therefore establishing methods of supporting those experiencing issues relating to infertility is crucial. Information provisions is necessary in supporting AYA in regards to coping mechanisms and the ability to self-manage, though this support should be widened to include family members and close relatives as all are impacted by the diagnosis. 


\section{Discussion}

The importance of psychosocial needs combined with the psychological wellbeing of survivors can hinder the ability to overcome the impact of the cancer treatments. Interacting with friends enables survivors to reintegrate and regain confidence, allowing them to re-establish themselves back into normal life ${ }^{11}$. The ability to sustain friendships during the transition emerged especially prominent, allowing adolescents to rise above the challenges and the residual effects of cancer treatment ${ }^{20}$. Galán et al. (2016) provided evidence of friendships and relationships helping improve the psychosocial issues survivors face ${ }^{21}$. The fear of 'losing touch' and unable to socialise with friends can lead to isolation and act as a barrier to re-entering normality ${ }^{22}$. It was found that relying on friends for support especially those with experience with cancer was important and that having contact mutually benefitted AYA survivors ${ }^{22}$.

Teenage Cancer Trust (2015) provided evidence of friendships and relationships helping improve the psychosocial issues survivors face ${ }^{14}$. However, if the survivors do not have access to these individuals the ability to develop these relationships becomes much more difficult post-cancer treatment. The introduction of a buddy system or the establishment of key workers will allow for an increase accessibility of support throughout one's cancer journey. In order for health care professionals, carers or peers to adequately aid survivors, the correct training is required to equip them with the skills to best support adolescents. Extending training to family, friends and partners is equally as important as it will impact on the day-to-day lives of survivors. This would allow individuals to selfmanage with the right tools and information which in turn would reduce the reliance of voluntary funding ${ }^{13}$.

NICE (2005) found that fertility and psychological issues were most common among survivors transitioning into normal life ${ }^{13}$. Though the NHS have begun to focus its agenda on developing means of combatting issues of infertility, anxiety and body image dissatisfaction, it is apparent that greater insight and investment is required to achieve the support necessary for a survivor to enter normality and succeed ${ }^{14}$.

Stinson et al. (2015) found that fear of infertility was a major theme among all the participants in the interviews, and access to care would ultimately improve psychosocial health of adolescents ${ }^{17}$. Results from Dudzinski (2004) identified that fertility issues were a major concern, which greatly impacts on the ability for survivors to envisage being a parent sometime in the future ${ }^{19}$. It is essential that resources are not all focussed on the development of the means of preserving female fertility, the introduction of counselling services will allow survivors to comprehend the challenges and discuss other options available.

Pacey (2007) followed the success of male fertility preservation and discussed different techniques that may in the future play a role in preserving fertility in female patients ${ }^{18}$. Oocyte cryopreservation and other techniques are now widely used to counter infertility in female cancer patients since this article's publication. An urgent referral is required for all those enrolled into the fertility preservation program with access also to counselling services to deliver necessary support.

Many AYA may appear to have managed well while on treatment, but the reality of the impact it has had on the patient only becomes apparent when they are no longer in contact with their treatment team, often referred to as 'hiatus in care' ${ }^{23}$. Cancer 
treatment can have a long-term effect on patients, therefore psychological and emotional wellbeing must be acknowledged at multiple stages following the completion of cancer treatment ${ }^{14}$. It is difficult to support AYA as young as 12-years-old to understand issues of infertility but more so ensuring capacity to make an informed decision to undergo fertility preserving treatment.

A 12-year-old may not have issues with dating or fertility but at a later stage in their life these issues will be more apparent, thus conducting follow ups consistently will enable those survivors to have access to support better suited to their needs ${ }^{17}$. It is often noted that psychological distress is missed during follow ups and therefore the implementation of screening for late effects as such can be beneficial ${ }^{24,25}$.

A study reviewed the function of religion and spirituality for AYA as a means of support post-cancer treatment ${ }^{26}$. Findings suggest that religion and spirituality can be used as a coping mechanism, often referred to as 'constructive coping', allowing one to grasp the meaning of the challenges they face ${ }^{26}$. When AYA are able to draw upon a coping mechanism they assume to be effective, it improves their overall emotional wellbeing ${ }^{22}$. This will enable survivors to move on from the issues they face, and not be stuck with the residual effects of the cancer. Though, the effectiveness of religion and spirituality is yet to be investigated, it may be the method that could help those survivors cope with infertility and psychosocial issues.

\section{Conclusion}

The systematic review aimed to investigate the support needs for adolescents' postcancer treatment. It was intended that the defined methodology and analysis would prove to form constructive conclusions.

The eagerness to continue a normal successful life post-cancer treatment seems to be over-shadowed by the fear of not being able to conceive offspring. This, in turn, can impact on the psychological wellbeing of survivors, thus signifying the need to develop ways in supporting these individuals. It is reassuring to note that progress has occurred and female fertility preserving treatment is now available. Although the issue of delaying treatment for fertility preservation may be detrimental to treatment outcomes.

The role of relationships and key workers were important to enabling survivors to selfmanage. Though many articles detached the needs of survivors and support options, a more focussed all-inclusive study is required to fully conclude and redevelop the current recommendations for survivorship.

Body image dissatisfaction and anxiety were common among the survivors, restricting the ability for them to secure relationships. Studies have commended the role of friendships during the cancer treatment process but also as a means to coping with issues relating to survivorship. Using a coping mechanism thought to be beneficial by the survivor often improves their overall wellbeing. Other modes of support were also mentioned which include buddy system, religion and spirituality and survivorship groups, though greater research is required to understand the effectiveness of these methods. There has been a great deal of investment and specialisation in AYA cancer treatment and support, though improved use of resources is essential to providing optimal care. 


\section{Acknowledgements}

none

\section{Financial Support}

None

\section{Ethical Standards}

Due to the nature of the study attainment of ethical approval was not appropriate.

\section{Conflicts of Interests}

none 
1. Cancer Research UK. (2015). Teenagers' and young adults' cancers statistics. [online] Available at: http://www.cancerresearchuk.org/healthprofessional/cancer-statistics/teenagers-and-young-adults-cancers\#headingThree [Accessed 4 Jul. 2016].

2. Grunfeld, E. (2006). Looking Beyond Survival: How Are We Looking at Survivorship? Journal of Clinical Oncology, [online] 24(32), pp.5166-5169. Available at: http://www.ncbi.nlm.nih.gov/pubmed/17093281 [Accessed 5 Jul. 2016].

3. Nathan, P., Hayes-Lattin, B., Sisler, J. and Hudson, M. (2011). Critical issues in transition and survivorship for adolescents and young adults with cancers. Cancer, [online] 117(S10), pp.2335-2341. Available at: http://onlinelibrary.wiley.com/doi/10.1002/cncr.26042/full [Accessed 27 Jul. 2016].

4. Al Omari, O. and Wynaden, D. (2014). The Psychosocial Experience of Adolescents with Haematological Malignancies in Jordan: An Interpretive Phenomenological Analysis Study. The Scientific World Journal, [online] 2014, pp.1-7. Available at: https://www.hindawi.com/journals/tswj/2014/274036/ [Accessed 31 Jul. 2016].

5. Clinton-McHarg, T., Carey, M., Sanson-Fisher, R., Shakeshaft, A. and Rainbird, K. (2010). Measuring the psychosocial health of adolescent and young adult (AYA) cancer survivors: a critical review. Health and Quality of Life Outcomes, [online] 8(1), p.25. Available at: http://www.ncbi.nlm.nih.gov/pmc/articles/PMC2850329/ [Accessed 9 Aug. 2016].

6. Bleyer, W. (2001). Cancer in older adolescents and young adults: Epidemiology, diagnosis, treatment, survival, and importance of clinical trials. Med. Pediatr. Oncol., [online] 38(1), pp.1-10. Available at: http://www.ncbi.nlm.nih.gov/pubmed/11835231 [Accessed 18 Aug. 2016].

7. Akobeng, A. (2005). Understanding systematic reviews and meta-analysis. Archives of Disease in Childhood, [online] 90(8), pp.845-848. Available at: http://adc.bmj.com/content/90/8/845.full [Accessed 15 Aug. 2016].

8. Aveyard, H. (2010) Doing a literature review in health and social care: a practical guide. $2^{\text {nd }}$ edn. Maidenhead: McGraw-Hill Open University Press. [Accessed 08 Sep. 2016].

9. The British Psychological Society, (2010). Code of Human Research Ethics. [online] pp.21-30. Available at: http://www.bps.org.uk/sites/default/files/documents/code_humanresearch_ethics.pdf [Accessed 19 Aug. 2016].

10. Critical Appraisal Skills Programme (CASP), (2012). Critical Appraisal Skills Programme (CASP). [online] Available at: http://www.casp-uk.net/\#!casptools-checklists/c18f8 [Accessed 09 Sep. 2016].

11. Fan, S. and Eiser, C. (2009). Body image of children and adolescents with cancer: A systematic review. Body Image, 6(4), pp.247-256. [Accessed 14 Aug. 
2016].

12. Kelly, D. (2013). Developing Age Appropriate Psychosexual Support for Adolescent Cancer Survivors: A Discussion Paper. The Journal of Sexual Medicine, 10, pp.133-138. [Accessed 14 Aug. 2016].

13. NICE (2005). Improving outcomes for children and young people. [online] Available at: https://www.nice.org.uk/guidance/csg7/resources/improvingoutcomes-in-children-and-young-people-with-cancer-update-773378893 [Accessed 24 Aug. 2017].

14. Teenage Cancer Trust, (2015). A blueprint of care for teenage and young adults with cancer. [online] Available at: https://www.teenagecancertrust.org/sites/default/files/Blueprint-of-Care.pdf [Accessed 2 Sep. 2016].

15. Department of Health (2010). The National Cancer Survivorship Initiative Vision. [online] Available at:

http://webarchive.nationalarchives.gov.uk/20100809113601/http://www.imp rovement.nhs.uk/cancer/LinkClick.aspx?fileticket=4apVUSvGcow\%3d\&tabid=2 14 [Accessed 24 Aug. 2017].

16. Barr, R., Ferrari, A., Ries, L., Whelan, J. and Bleyer, W. (2016). Cancer in Adolescents and Young Adults. JAMA Pediatrics, 170(5), p.495. [Accessed 14 Aug. 2016].

17. Stinson, J., Jibb, L., Greenberg, M., Barrera, M., Luca, S., White, M. and Gupta, A. (2015). A Qualitative Study of the Impact of Cancer on Romantic Relationships, Sexual Relationships, and Fertility: Perspectives of Canadian Adolescents and Parents During and After Treatment. Journal of Adolescent and Young Adult Oncology, 4(2), pp.84-90. [Accessed 14 Aug. 2016].

18. Pacey, A. (2007). Fertility issues in survivors from adolescent cancers. Cancer Treatment Reviews, 33(7), pp.646-655. [Accessed 14 Aug. 2016].

19. Dudzinski, D. (2004). Ethical issues in fertility preservation for adolescent cancer survivors: oocyte and ovarian tissue cryopreservation. Journal of Pediatric and Adolescent Gynecology, 17(2), pp.97-102. [Accessed 14 Aug. 2016].

20. Choquette, A., Rennick, J. and Lee, V. (2016). Back to School After Cancer Treatment. Cancer Nursing, 39(5), pp.393-401 [Accessed 14 Aug. 2016].

21. Galán, S., de la Vega, R., Tomé Pires, C., Racine, M., Solé, E., Jensen, M. and Miró, J. (2016). What are the needs of adolescents and young adults after a cancer treatment? A Delphi study. Eur J Cancer Care. [Accessed 14 Aug. 2016].

22. Taylor, R., Pearce, S., Gibson, F., Fern, L. and Whelan, J. (2013). Developing a conceptual model of teenage and young adult experiences of cancer through meta-synthesis. International Journal of Nursing Studies, 50(6), pp.832-846. [Accessed 14 Aug. 2016].

23. Moody, L., Turner, A., Osmond, J., Hooker, L., Kosmala-Anderson, J. and Batehup, L. (2014). Web-based self-management for young cancer survivors: consideration of user requirements and barriers to implementation. Journal of Cancer Survivorship, 9(2), pp.188-200. [Accessed 14 Aug. 2016].

24. Patterson, P., McDonald, F., Zebrack, B. and Medlow, S. (2015). Emerging Issues Among Adolescent and Young Adult Cancer Survivors. Seminars in Oncology Nursing, 31(1), pp.53-59. [Accessed 14 Aug. 2016]. 
25. Michel, G. and Vetsch, J. (2015). Screening for psychological late effects in childhood, adolescent and young adult cancer survivors. Current Opinion in Oncology, 27(4), pp.297-305. [Accessed 14 Aug. 2016]

26. Cotton, S., Zebracki, K., Rosenthal, S., Tsevat, J. and Drotar, D. (2005). Religion/spirituality and adolescent health outcomes: a review. Journal of Adolescent Health, 38(4), pp.472-480. [Accessed 14 Aug. 2016]. 
1

2

3

4

5

6

7

8

9

10

11

12

13

14

15

16

17

18

19

20

21

22

23

24

25

26

27

28

29

30

31

32

33

34

35

36

37

38

39

40

41

42

43

44

45

46

47

48

49

50

51

52

53

54

55

56

57

58

59

60

61

62

63

64

65

\section{Appendices}

Appendix 1: CASP quality assesment tool 


\section{Appendix 1: CASP quality assesment tool}

(A) Are the results of the review valid?

Screening Questions

1. Did the review address a clearly focused question?

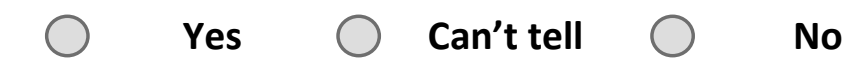

HINT: An issue can be 'focused' In terms of $\bullet$ The population studied

- The intervention given

- The outcome considered

2. Did the authors look for the right type of papers?

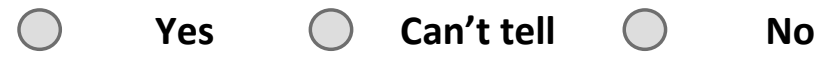

HINT: 'The best sort of studies' would

- Address the reviews question

- Have an appropriate study design (usually RCTs for papers evaluating interventions)

Is it worth continuing?

Detailed questions

3. Do you think all the important relevant studies were included?

\section{Yes $\bigcirc$ Can't tell $\bigcirc$ No}

HINT: Look for

- Which bibliographic databases were used

- Follow up from reference lists 
- Personal contact with experts

- Search for unpublished as well as published studies

- Search for non-English language studies

4. Did the review's authors do enough to assess the quality of the included studies?
Yes
Can't tell
No

HINT: The authors need to consider the rigour of the studies they have identified. Lack of rigour may affect the studies' results. ("All that glisters is not gold" Merchant of Venice Act II Scene 7)

5. If the results of the review have been combined, was it reasonable to do so?

\section{Yes $\bigcirc$ Can't tell $\bigcirc$ No}

HINT: Consider whether

- The results were similar from study to study

- The results of all the included studies are clearly displayed $\bullet$ The results of the different studies are similar

- The reasons for any variations in results are discussed

(B) What are the results?

6. What are the overall results of the review?

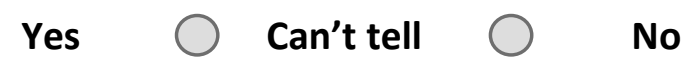

HINT: Consider

- If you are clear about the review's 'bottom line' results 
- What these are (numerically if appropriate)

- How were the results expressed (NNT, odds ratio etc)

\section{How precise are the results?}

HINT: Look at the confidence intervals, if given

(C) Will the results help locally?

8. Can the results be applied to the local population?

Yes $\bigcirc$ Can't tell $\bigcirc$ No

HINT: Consider whether

- The patients covered by the review could be sufficiently different to your population to cause concern $\bullet$ Your local setting is likely to differ much from that of the review

9. Were all important outcomes considered?

\section{Yes $\bigcirc$ Can't tell $\bigcirc$ No}

HINT: Consider whether

- Is there other information you would like to have seen

10. Are the benefits worth the harms and costs?

\section{Yes $\bigcirc$ Can't tell $\bigcirc$ No}

HINT: Consider

- Even if this is not addressed by the review, what do you think? 
1

2

3

4

7

8

10

11

12

13

14

15

16

17

18

19

20

21

22

23

24

25

26

27

28

29

30

31

32

33

34

35

36

37

38

39

40

41

42

43

44

45

46

47

48

49

50

51

52

53

54

55

56

57

58

59

60

61

62

63

64

65 